\title{
CONJUNTO HABITACIONAL MÁRIO AMATO E A ANÁLISE DE HABITAÇÃO DE INTERESSE SOCIAL EM PRESIDENTE PRUDENTE-SP
}

\author{
Valquíria Patrícia Félix', Sibila Corral de Arêa Leão Honda², Marcela do Carmo Vieira² \\ ${ }^{1}$ Discente do curso de Arquitetura e Urbanismo da Universidade do Oeste Paulista - UNOESTE. ${ }^{2}$ Docentes do curso de \\ Arquitetura e Urbanismo da Universidade do Oeste Paulista
}

\section{RESUMO}

O processo de urbanização brasileiro tem gerado sérios problemas habitacionais, principalmente para população mais carente. Deficiência nas políticas e programas de habitação social também têm auxiliado no déficit de moradias urbanas. Desde a década de 1930, implantação de grandes conjuntos em áreas além malha urbana não proporciona a inclusão populacional desejada. A partir dos estudos relativos à habitação de interesse social, focando principalmente na Companhia de Desenvolvimento Habitacional e Urbano (CDHU), do Governo Paulista, no ano de 1993, este artigo visa a iniciar discussão a respeito da implantação de conjuntos habitacionais na estrutura urbana e a tipologia das unidades residenciais; tendo estudo de caso o conjunto Mário Amato em Presidente Prudente, no interior do Estado. Importante analisar a implantação do empreendimento para a baixa renda e sua tipologia projetual. A metodologia está embasada em pesquisa teórico-conceitual, documental e de campo, com mapeamentos, e relacionando todas as informações levantadas.

Palavras-chave: Expansão Urbana, Projeto Urbano, Projeto Arquitetônico, Segregação Urbana, Habitação Social.

\section{INTRODUÇÃO}

O processo de urbanização no Brasil tem ocorrido de forma bastante acelerada a partir do final do século XIX. A industrialização brasileira gerou grande inchaço populacional nas cidades, resultando em forte déficit habitacional urbano. Ao mesmo tempo, políticas públicas voltadas ao embelezamento e à instalação de infraestrutura urbanos incentivaram a expulsão da população carente, direcionando-a às periferias, inclusive para áreas clandestinas (VILLAÇA, 1999).

Fortes processos de segregação intra-urbana têm ocorrido nas cidades brasileiras, motivados principalmente por questões sociais e econômicas (MARQUES e TORRES, 2005; BONDUKI, 2004).

Durante a "Era Vargas" (1930-1945), no entanto, o Estado brasileiro começou a buscar alternativas para a redução do déficit de moradia por meio de ações diretas. Em 1938, foram criadas as Carteiras Prediais dos Institutos de Aposentadoria e Previdência (IAP's) que seriam as responsáveis pela construção e financiamento de novas unidades habitacionais nos centros urbanos. Em 1946, já no Governo do Presidente Eurico Gaspar Dutra, foi criada a Fundação da Casa Popular (HONDA, 2011). 
No início da década de 1960, durante o Governo de Jânio Quadros, foi feita uma reestruturação na política habitacional por meio do Plano de Assistência e da criação do Instituto Brasileiro de Habitação (IBH), mas que não obtiveram sucesso devido ao acelerado processo de urbanização no país que gerava constante crescimento da demanda por moradias (KOWARICK e BONDUKI, 1994).

No entanto, o padrão de expansão territorial urbana periférica foi consolidado, baseado na autoconstrução de moradias em terrenos clandestinos, desprovidos de infraestrutura e serviços públicos. Verifica-se também processo de verticalização urbana e de incremento nas vias de circulação de automóveis particulares, como o Plano de Avenidas de São Paulo (VILLAÇA, 1999; HONDA, 2011).

Em 1964, com o Regime Militar, a política habitacional vigente foi rejeitada, sendo que a nova, ideologicamente, visava a "facilitar o acesso à casa própria, por meio da construção de habitações populares e da eliminação das favelas, auxiliar a recuperação da economia e favorecer a estabilidade social" (HONDA, 2011, p.22). Foram criados o Sistema Financeiro de Habitação (SFH) e o Banco Nacional da Habitação (BNH).

De forma geral, os locais em que conjuntos habitacionais eram executados se situavam na franja urbana ou além da malha, e sem infraestrutura ou equipamento urbanos, criando sérios problemas para os moradores e para os Governos municipais. Tal padrão perdurou desde a década de 1930 até os primeiros anos da década de 1990, com os programas do Governo Fernando Collor de Mello.

Em 1986, o BNH foi extinto, e, em 1987, foi retomada a discussão sobre reforma urbana e a questão da habitação. Em 1988 a nova Constituição Federal foi sancionada. A Constituição Estadual Paulista foi aprovada no ano seguinte, ano que também foi criada a Companhia de Desenvolvimento Habitacional e Urbano (CDHU), da Secretaria de Habitação do Estado de São Paulo (HONDA, 2011).

Baseado neste contexto, este artigo visa a contribuir para a análise da produção da habitação de interesse social em cidades médias, verificando a questão da implantação desses empreendimentos na estrutura urbana e o projeto base das unidades residenciais como reforço do processo de segregação espacial, tendo como estudo de caso o conjunto habitacional Mário Amato, executado com financiamento da Companhia de Desenvolvimento Habitacional e Urbano (CDHU), do Governo Estadual Paulista, no ano de 1993, em Presidente Prudente, município do Estado de São Paulo. 


\section{METODOLOGIA}

A metodologia utilizada nesta pesquisa está baseada em aprofundamento teórico; investigação prática, procurando efetuar a análise de casos estabelecidos, por meio de pesquisa documental, levantamentos de campo e mapeamentos; e análises e elaboração do corpo de argumentação.

\section{PRODUÇÃO DO ESPAÇO URBANO DE PRESIDENTE PRUDENTE}

Presidente Prudente é uma cidade no oeste paulista, na Alta Sorocabana. Sua base de colonização foi apoiada na produção agropecuária e na implantação da estação ferroviária no início do século XX, inaugurada em janeiro de 1919. A estrutura urbana foi diretamente dependente da abertura de dois loteamentos: Vila Goulart e Vila Marcondes. Em 1921, o município foi criado legalmente, como centro político e administrativo regional.

Entre a década de 1920 e primeira metade da de 1950, a cidade apresentou significativa expansão territorial, sem planejamento e sem regularização legal; enquanto que o período compreendido entre a segunda metade da década de 1950 e a de 1960 ficou marcado por pequeno crescimento espacial urbano, quando comparado ao verificado nos anos 1940 (HONDA, 2000).

Entre as décadas de 1960 e 1970, percebe-se aumento da população, ampliação do quadro industrial e desenvolvimento das atividades terciárias. Em 1968 foi iniciado o Plano Diretor de Desenvolvimento Integrado (PDDI) no município, aprovado em 1973. Durante a década de 1970, a cidade conheceu expansão territorial urbana sem precedentes (HONDA, 2011).

Durante a evolução urbana de Presidente Prudente, vários conjuntos habitacionais foram construídos, sendo que o primeiro foi executado em 1968. A maior parte dos conjuntos habitacionais até 1982 foram implantados na região oeste da cidade. Entre os anos de 1983 e 1989 não houve aprovação de novos empreendimentos, com retomada do processo nesse último ano (TORREZAN, 1992; MARISCO, 2003; FERNANDES, 1998).

Durante os anos de 1990 e 1992, dez conjuntos habitacionais foram aprovados e sua construção iniciada em Presidente Prudente, incluindo financiamentos dos Governos Federal e Estadual; deste por meio da Companhia de Desenvolvimento Habitacional e Urbano (CDHU): Jardim Cambuci, com 80 unidades residenciais; Brasil Novo, com 250 unidades; Sítio São Pedro, com 232 unidades; Jardim Jequitibás II, com 386 unidades; Ana Jacinta II, com 104 unidades; e Mário Amato, com 500 unidades e foco desta pesquisa (HONDA, 2011). 
Entre 1993 e 1996 houve aprovação de loteamentos municipais com dação em uso. A partir de 1997, mais doze empreendimentos foram construídos. Verifica-se a construção de mais de 15.000 unidades habitacionais na cidade entre 1968 e 1999 (HONDA, 2011).

A tendência histórica de expansão da malha urbana de Presidente Prudente demonstra pressão a sul para loteamentos e condomínios para as classes mais altas, enquanto os conjuntos habitacionais e loteamentos de interesse social têm sido implantados principalmente nos setores norte e oeste, concentrando áreas de segregação socioespacial.

Interessante notar, no entanto, que o conjunto habitacional Mário Amato foi executado no setor sudoeste, juntamente com os conjuntos Ana Jacinta, financiado pelo Programa de Ação Imediata para Habitação (PAIH), do Governo Federal, e Ana Jacinta II, também financiado pela CDHU. Todos foram implantados nos anos de 1992 e 1993, num total de 3.104 unidades habitacionais.

\section{CONJUNTO HABITACIONAL MÁRIO AMATO}

Conforme já foi dito, o conjunto habitacional Mário Amato foi financiado pelo Governo Estadual Paulista, por meio da CDHU, entre os anos de 1992 e 1993. Foi implantado na região sudoeste do município, além malha urbana na época (Figura 1), juntamente com outros dois conjuntos de moradia social: Ana Jacinta e Ana Jacinta II, também executados no mesmo período.

O Mário Amato apresenta 500 unidades, e visou a atender famílias com renda de até três salários mínimos, excluídas de outros programas. Os três conjuntos construídos na mesma região e período apresentam mesma tipologia construtiva, materiais, técnicas e projeto das edificações (Figura 2). O projeto apresenta apenas um dormitório, banheiro e sala conjugada com cozinha, em total de $29,28 \mathrm{~m}^{2}$.

A localização do empreendimento demonstra grande segregação socioespacial urbana, por meio de exclusão da população identificada como beneficiada, reforçando o processo de segregação centro versus periferia (VILLAÇA, 1998). O tamanho da unidade residencial também demonstra o descaso social e político com essa população.

Nota-se também a formação de centralidade urbana na região por meio dos levantamento executados no loteamento. Esse fato se deve à grande distância existente entre os empreendimentos e o centro da cidade ou outras áreas de serviços e comércio. $\mathrm{O}$ isolamento reforça a segregação espacial, assim como a falta de mobilidade urbana identificada. 


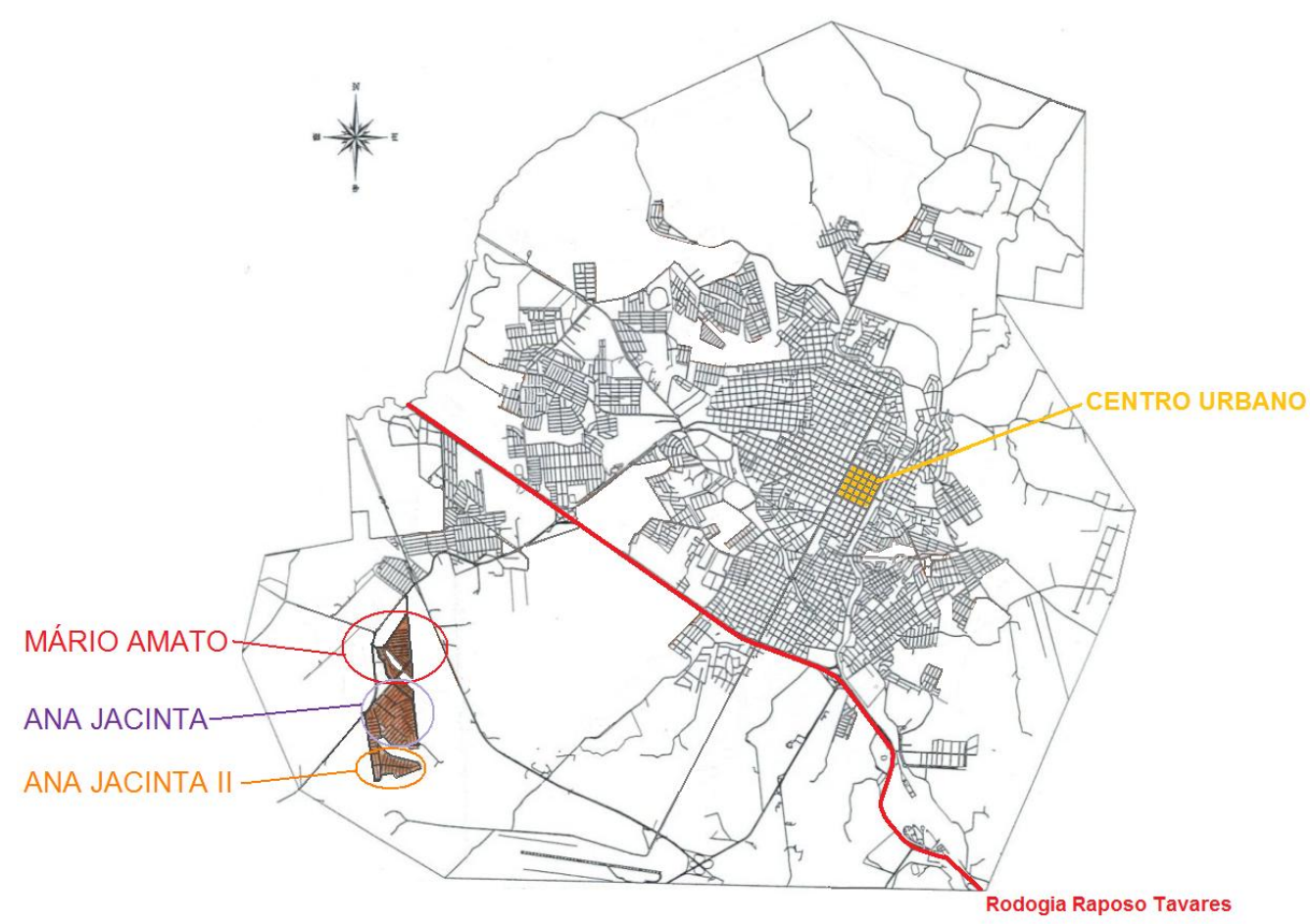

Figura 1. Malha urbana em Presidente Prudente em 1992

Fonte: HONDA, 2011; modificado pelas autoras, 2013

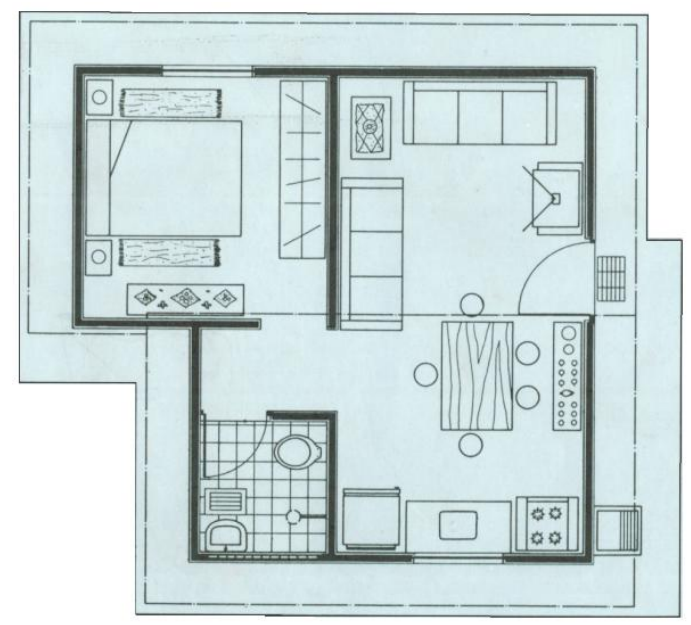

Planta Baixa - unidade residencial - Manual do Proprietário Área: $29,28 \mathrm{~m} 2$

Figura 2. Planta das unidades residenciais executadas no conjunto habitacional Mario Amato Fonte: Manual do Proprietário

Verifica-se atualmente que o empreendimento ainda pode ser caracterizado como localizado na franja urbana de Presidente Prudente. No entanto, por estar ladeado de outros empreendimentos de habitação social, há reforço nessa localização, com investimento nas unidades habitacionais por parte de seus possuidores, mesmo que não proprietários legais. 
Em levantamentos executados nesta pesquisa, pode ser observado grande número de unidades com alterações e ampliações, resultando em apenas 8,6\% delas originais.

\section{CONSIDERAÇÕES FINAIS}

Devido aos levantamentos elaborados nesta pesquisa, foi possível a compreensão da realidade de um conjunto habitacional, tendo como foco de análise o conjunto Mário Amato na cidade de Presidente Prudente-SP.

Pode-se observar que, apesar das dificuldades encontradas por uma população carente, seja na localização do empreendimento na estrutura urbana, seja no processo segregador intra-urbano (VILLAÇA, 1998), o conjunto habitacional assume vida própria, estabelecendo uso e ocupação do solo urbanos de forma diferente ao projetado, ampliando a ocupação por meio de verticalização das construções, assim como o uso, possibilitando a criação de subcentralidade.

Dessa forma, contata-se que a continuidade na implantação de empreendimentos de habitação social além malha urbana mantém seus moradores à margem da cidade; que são impelidos a participar ativamente da produção de espaço urbano, inclusive de forma não legalizada.

\section{REFERÊNCIAS BIBLIOGRÁFICAS}

BONDUKI, N. Origens da habitação social no Brasil: arquitetura moderna, lei do inquilinato e difusão da casa própria. $4^{a}$.edição. São Paulo: Estação Liberdade, 2004.

FERNANDES, S.A.S. Territorialização das políticas habitacionais em Bauru e Presidente Prudente - $a$ atuação da CDHU, COHAB-CRHIS e COHAB-Bauru. Presidente Prudente: UNESP, 1998 (Dissertação de Mestrado).

HONDA, S.C.A.L. A centralidade urbana em Presidente Prudente. São Paulo: UPM, 2000 (Dissertação de Mestrado).

HONDA, S.C.A.L. Habitação de Baixa Renda como Produto do Capital - o Programa de Arrendamento Residencial (PAR) em Presidente Prudente-SP. São Paulo: UPM, 2011 (Tese de Doutorado).

KOWARICK, L.; BONDUKI, N. Espaço urbano e espaço político: do populismo à redemocratização. In: KOWARICK, L. (org.). As lutas sociais e a cidade: São Paulo - passado e presente. 2a. edição revisada. São Paulo: Ed. Paz e Terra, 1994. p.147-177.

MARISCO, L.M.O. A norma e o fato: abordagem analítica da segregação sócio-espacial e exclusão social a partir dos instrumentos urbanísticos. Presidente Prudente: FCT-UNESP, 2003 (Tese de Doutorado). 
MARQUES, E.; TORRES, H. (org). São Paulo: Segregação, Pobreza e Desigualdades Sociais. São Paulo: Editora SENAC São Paulo, 2005.

TORREZAN, R.M. Reestruturação da cidade: localização de conjuntos habitacionais, estrutura e crescimento urbano em Presidente Prudente. Presidente Prudente: FCT/UNESP, 1992 (Monografia de Graduação).

VILLACA, F. Espaço Intra-Urbano no Brasil. São Paulo: Nobel, 1998.

VILLAÇA, F. Uma contribuição para a história do planejamento urbano no Brasil. In: DÉAK, C; SCHIFFER, S.R (orgs). O Processo de Urbanização no Brasil. São Paulo, EDUSP, 1999, p.169-243. 